\title{
THE WHITE PINE WEEVIL: A REVIEW OF CURRENT KNOWLEDGE ${ }^{1}$
}

\author{
By R. M. BELYEA and C. R. SULLIVAN 2
}

R. M. Belyea was born in Fredericton, N.B., in 1920. He lived most of his life in Toronto, and graduated from the University of Toronto, in Honour Biology, in 1942. He served in the Royal Canadian Navy, 1942-45. He received a Ph.D. in Forest Entomology, University of Toronto, 1951, and joined the staff of the Forest Insect Laboratory, Sault Ste. Marie, Ontario, in 1946. He has been the Officer-in-Charge of the Laboratory since 1952.

C. R. Sullivan was born in New Liskeard, Ontario, in 1925 and lived most of his life in Englehart, Ontario. He served in the R.C.A.F., 1943-45. He received a B.S.A. degree from O.A.C. in 1949 and an M.S.A. degree from the University of Toronto in 1951. In 1953, he registered at McGill University and is presently engaged in studies leading to a Ph.D degree in Entomology. He joined the staff of the Forest Insect Laboratory, Sault Ste. Marie, Ontario, in 1947.

The white pine weevil, Pissodes strobi Peck, has long been recognized as the most important insect pest of eastern white pine throughout its range in eastern North America. Eastern white pine, Pinus strobus L., is the favored host of the insect, although Norway spruce, Picea abies (L), Scots pine, Pinus sylvestris L., and jack pine, Pinus banksiana Lamb., the latter particularly in the Lake States of the United States, are also severely attacked and may, at times, be as severely injured as white pine. All pines and spruces of the more northern regions of the continent, both native and introduced, are liable to attack, but white spruce, Picea glauca (Moench) Voss, black spruce, Picea mariana (Mill.) B.S.P., and red pine, Pinus resinosa Ait., are rarely injured.

The white pine weevil was first described as a forest insect of importance in 1817 by W. D. Peck, Professor of Natural History and Botany at Harvard University. Since that time, much has been written about its life history and habits, and possibilities of its control. Peck's original description of the insect and its damage (13) is an interesting document written before the ravages of the weevil were widespread, and although he did not completely understand its life history, he clearly recognized its probable importance to the pine forests of the east. It was not, however, until the turn of the Twentieth Century that the weevil was considered a serious pest and one of the most important factors limiting the successful growing of white pine, particularly in reforestation and plantation programs.

We propose to consider here, briefly, the historical development of ideas concerning the weevil and its control and some of the possibilities of protecting young white pine stands, both natural and planted, from the depredations of this insect.

\footnotetext{
${ }^{1}$ Contribution No. 248, Forest Biology Division, Science Service, Department of Agriculture, Ottawa, Canada. Paper presented at the Annual Meeting of the Canadian Institute of Forestry, Saskatoon, Sask., October 6, 1955.

- Forest Insect Laboratory, Sault Ste. Marie, Ontario.
} 
The white pine weevil is a species native to North America, which is distributed throughout the range of eastern white pine and has, therefore, undoubtedly always been an integral part of the forest environment. An account of its life history was first given in detail in 1907 by Hopkins (10) and has since been corroborated by a number of other workers. Briefly, the life history is as follows. It completes one generation per year, hibernating during the winter as an adult on the surface of the mineral soil within the duff and litter, commonly at the base of the tree on which it last fed. Emergence of the adults from hibernation varies with season and location, but generally occurs during the latter half of April, when the adults normally move up the trees under which they overwintered. Under favorable weather conditions, feeding and copulation soon begin on the upper part of the terminal shoot, and about a week later the females begin depositing eggs in the same general area where feeding commenced. From one to three eggs are deposited at one time under the outer layers of the bark in small chambers excavated at the base of normal feeding punctures. Over a period of about six weeks, each female may deposit up to about 200 eggs, and small resin droplets on the terminals readily mark trees in which adults have fed and oviposited. Feeding and oviposition together seldom cause the death of the terminal. The eggs hatch in about two weeks and the small larvae soon become arranged in a ring about the leader and thereafter move downwards as a group, feeding internally on the inner bark and leaving the outer bark intact. Normally, about five or six weeks are required to attain larval maturity, by which time the infested leaders have been killed.

Transformation from mature larvae to adults occurs in pupal chambers constructed within the pith or wood of the dead leader. In about two weeks the new-generation adults are formed, but do not emerge from the leader until August or September.

Members of the new adult population do not mate and oviposit in the autumn-their activity at that time is limited to feeding on the old growth and on the now-matured growth of the current year. When weather conditions become unfavorable in late October and November, they move to the ground to suitable hibernation sites.

During both spring and autumn, adult activity is not limited to a single tree-feeding and oviposition may occur on several different trees, the adults moving from tree to tree by crawling on the ground or by flying. Although adults are capable of relatively long flight, possibly up to several hundred feet, short flights to nearby trees are most common.

White pine weevil injury to the tree results, therefore, from the killing, during larval feeding, of the tree leader. Dead leaders, discolored and drooping, are very conspicuous late in the season in heavily attacked stands. Customarily, two or more years' growth of the main stem is destroyed, and as a consequence, one of the laterals of the uppermost whorl surviving attack may assume leadership resulting in a crooked stem, or two or more laterals may compete for leadership resulting in a forked stem. Trees that are weevilled repeatedly develop into multiple-top shrubs of no value.

Weevil attack seldom results in the death of the tree, but leader killing 
naturally results in a serious reduction of height growth. Deformity of the tree depends on the severity and frequency of weevilling when the tree is young. Even though lightly weevilled trees may appear to overcome a crooked stem by the time they are of merchantable size, lumber sawn from such trees contains serious defects. Cross grain, large knots, and compression wood that is brittle and checks badly are regularly present at the crook $(11,17)$.

The first serious attack by the weevil usually occurs when white pine trees are about five years of age and three feet or less in height. Severity of attack increases rapidly during succeeding years, but drops off by the time trees have reached a height of 20 feet and is often negligible by the time they are 25-30 feet in height. Severe damage by the weevil may, therefore, occur during a period of some 15 to 20 years in the growth of a stand.

During the first 35 years of the present century, considerable interest was shown in the white pine weevil problem, particularly in the United States, and as a consequence, an extensive literature developed on its life history, habits, injury, and control, both by silvicultural and chemical means.

It was early recognized that the weevil did not become a problem in the eastern United States until the middle of the Ninteenth Century when fields cleared for agriculture were abandoned and were seeded in for the most part by white pine. Such stands were generally poorly stocked and the trees were repeatedly and severely weevilled. Added to the acreage of such poorly stocked new stands were the many acres of plantations established early in the Twentieth Century, and both provided abundant breeding sites for the insect. Observations made during the 1920's (1) indicated that during the previous 50 years the incidence of weevilling of pine had greatly increased.

Observation in both natural and planted pine stands early in the century led to certain conclusions regarding the habits of the weevil which have been the basis for concepts regarding the susceptibility of trees to attack and the possibilities of silvicultural control of the insect, even to the present day. As early as 1918 (7), it was recognized that in natural, open stands where the crowns were all free, the trees were equally subject to attack, while in denser stands the percentage of trees suitable for the development of the weevil was smaller, and in very dense stands injury was practically absent. It was concluded that close planting was the most economical and effective method of controlling the weevil in forest plantations.

It was also early recognized $(7,11)$ that, in contrast to trees growing in full sunlight, trees growing in mixture with hardwoods were relatively free from attack, injury decreasing with increasing shade. Recommendations were made in the early 1920's (8) that some system of silviculture should be used that would provide shade to the young pines during their susceptible period, that is until they reach 15-20 years of age or between 20 and 30 feet in height. These recommendations carried the warning that the density of shade tolerated by the pines would vary with site and would have to be determined for each site, and should not be such that the growth of the pines would be unduly retarded.

During the succeeding 15 years, various workers in the New England and 
Lake States supported these views. In 1930, MacAloney (11) published the results of extensive studies of the weevil, its life history and habits, and his observations on a large number of sample plots in both natural and planted stands throughout the eastern United States and Canada. While recognizing that dense stocking in pure stands of pine tends to keep permanent injury by the weevil at a minimum, he stated that, to ensure good protection, very dense stands would be required in most areas of heavy weevil populations, and that such stands were financially practical only when procured naturally. He concluded that the most advantageous and the cheapest way to protect white pine from the weevil was to grow it in mixture, preferably with species that would be of value in the final crop, and warned that early and successive thinnings, particularly in mixture with hardwoods, would be necessary so that the pines would not be crowded out. He found that several mixtures of both hardwoods and conifers with white pine had been quite successful in protecting the pine from weevil damage, and that in such mixtures the white pine cleans its bole relatively early, so that clear lumber may be expected from crop trees. He recognized that the accompanying tree species must be faster growing than the pine in the early years if both are the same age, or if slower growing, must be considerably older at the time the white pines become liable to attack, so that they will be taller during the period of weevil attack and so shade the pines. MacAloney also noted that adult weevils fed and oviposited, even in experimental cages, more readily on the robust, vigorous leaders found in open-growing trees than on the thin leaders associated with pine grown under shade.

During the past 35 or 40 years, attention has been directed primarily to the plantation growing of white pine and numerous attempts have been made both in the United States and Canada to grow pine satisfactorily free from weevil damage in various kinds of mixtures. In most cases these attempts have been either not successful or only moderately so, and the planting of white pine as a plantation species has been largely abandoned because of the weevil. Unfortunately, it has been replaced in many areas, including southern Ontario, by red pine, which is now nearly as badly off as white pine because of serious damage by the European pine shoot moth, Rhyacionia buoliana Schiff., an insect introduced into North America early in this century.

Until quite recently, little detailed research work has been undertaken to establish the reasons for the apparent protection from weevil damage afforded white pine trees growing in certain shaded conditions. The many plantations of various mixtures of both softwood and hardwood species with white pine, which have been planted with the object of providing shaded conditions, were established with no clear understanding of why such conditions were a deterrent to weevil activity and abundance, or of what degree of shading was actually required under varying conditions of soil, exposure, tree species in the mixture, etc. Such planting experiments have, therefore, been of an empirical nature, and as is the case with many empirical experiments, have shed little light on the real basis of the problem.

From 1935 to 1948 , observational studies of weevil attack in white pine were carried out at the Petawawa Forest Experiment Station in Ontario, records 
being maintained of the annual attack in each tree in open-growing natural regeneration and in white pine understories under various types of overstory. In general, the studies (15) corroborated earlier observations, illustrating the dangers inherent in establishing white pine plantations in the open, where injury is likely to be more severe in the better trees, and the unsatisfactory results of intermixing white pine with rapidly growing red pine, or planting it under rapidly growing aspen or other hardwoods, where weevilling may be light but survival of the white pine very poor. Checks of the relationship between weevil attack and leader diameter showed that attack was more severe in thick, long leaders than in thin, short ones. It was quite clear that the observation that white pine under hardwood and other shade is less susceptible to attack required careful study to determine whether the relationship is a direct one between the weevil and the physical environment, an indirect one involving growth and vigor of the understory trees, or a combination of both. Such relationships can only be understood when the physical and biological requirements of the weevil are carefully defined in terms of measureable factors of the environment.

In 1951, the Forest Insect Laboratory, Sault Ste. Marie, Ontario, initiated a study program at the Petawawa Forest Experiment Station designed to answer these questions. This program is still in progress, and it is expected that it will continue for some years to come. Valuable information has already been obtained from both field and laboratory studies.

To date, the investigation has been concerned chiefly with a study of the biology of the weevil and the effects of physical factors on its activity and behavior. Field methods were designed to assess the influence of air and bark temperatures, light, and moisture on the activity of adults both in the spring and autumn in open-grown stands. Studies dealing with the movement of individuals during the seasons were simplified by marking adults with radioactive materials. Invaluable assistance was provided to this part of the program by research officers of the Chalk River plant of Atomic Energy of Canada Ltd. (18). Observations were also made to determine the relation between weather and rate of larval development. These studies have already established the conditions of temperature, light, and humidity under which weevil adults carry on their normal activities of feeding, copulation, oviposition, flight, etc., and the type of weather necessary to create conditions favorable for these activities in the field. Briefly, it is now known that adult feeding, copulation, and oviposition are governed largely by bark temperature of the leader and by atmospheric moisture, and that of these three types of activity, oviposition is the most closely governed, occurring most commonly only at bark temperatures between $25^{\circ}$ and $29^{\circ} \mathrm{C}$ associated with $20 \%-35 \%$ R.H., a comparatively narrow range of conditions. The conditions under which adults oviposit are of prime importance, since it is known that considerable feeding and probably copulation as well take place on pine leaders in shaded stands where eggs are seldom deposited. Close study of terminal bark temperature and humidity in relation to prevailing weather has shown that conditions favorable to weevil egg laying commonly occur in open-grown pine stands on clear, calm days during the spring and early summer. 
Phenological observations of the opening of hardwood leaves, notably aspen and red oak, in relation to weevil oviposition in adjacent open stands have shown that oviposition coincides roughly with the time of leaf opening and is largely over before the hardwood canopy is complete. In mixed stands, shading of the pine leaders alters considerably the bark temperature and humidity of the leaders, since the radiant heating effect of the sun is reduced in proportion to the amount of shade. Further studies are therefore required to establish whether or not the amount of shade provided by a partial hardwood canopy at the time of egg laying is sufficient to alter habitat conditions enough during cool spring weather to create conditions unfavorable to weevil oviposition, and thus at least partially explain the protection afforded to understory pine trees by a hardwood overstory. With these studies must still be combined the direct effect of the attributes of the white pine tree, at present considered primarily a question of leader diameter, before a full understanding will be possible of why shade provides a measure of protection from weevil attack to pine trees.

Preliminary studies of light conditions in young pine stands growing as understories have shown that if insolation is reduced by $60 \%$ to $80 \%$, as has been found when the canopy consisted of red oak and mixtures of hardwoods and softwoods, during clear days when the canopy is fully developed, weevil damage is negligible; but if the insolation is reduced by only $25 \%$ to $50 \%$, as has been found when the canopy consisted of more widely spaced aspen, weevil damage may be appreciable, but still only of the order of $10 \%$ of that experienced by trees in the open. Obviously, considerable work is still required to establish exactly why shading provides protection from attack by the weevil to young pine trees and what degree of shading is necessary for adequate protection. However, the progress of the research program to date is encouraging enough to suggest that it will be soon possible to define, rather exactly, the condition of shading required to keep weevilling to a tolerable minimum. The problem of establishing how the defined condition of shading may be provided to young white pine trees during the time they are most susceptible to attack will then be a silvicultural one; it will be immediately apparent that, basically, this is not a new problem. In general terms it has been recognized for nearly half a century, but as a result of the present studies, it should be possible to attack the problem knowing more exactly what conditions must be created.

Many things must be considered in solving this problem. What is required is to establish at the time of planting white pine seedlings, or earlier, a "nurse" crop that will provide minimal required shading conditions at least until the pines have outgrown their most susceptible growth period, and that will at the same time allow the pine to grow as rapidly as possible. Ideally, both the "nurse" crop and the pine should provide a valuable cut. If underplanting an existing stand is contemplated, the same general requirements will prevail, the overstory stand being thinned in accordance with shading requirements.

Such mixed stands will require close observation and thinnings of the "nurse" crop during the early years of their establishment, so that only that degree of shading required to discourage the weevil is maintained, thus allowing the best possible growth of the pine. It is possible that many of the past 
attempts to grow such mixtures might have been more successful from the point of view of the pine if real attempts had been made for 15 to 20 years after establishment to see that the white pine were sufficiently open to allow them to grow.

Choice of "nurse" crop species for planting will depend largely on the qualities of the site to be planted; research will be required on the growth characteristics of potential "nurse" crop tree species, as well as of white pine, on various sites, in order that intelligent selection of species may be made. The "nurse" crop species must be chosen in relation to its growth characteristics on the selected site, as well as the characteristics of white pine on the same site.

Underplanting of existing hardwood stands will probably present fewer problems than the establishment of plantations, since the "nurse" crop will be already established and much will be known of its growth habits on the particular site. If the site should be good for white pine, it would appear that planting after thinning to obtain the required shade, and maintenance of the proper shade for the required period of time, should lead to a successful pine stand.

A satisfactory solution to the problem of growing white pine successfully in mixture cannot be expected in the immediate future. We are, therefore, faced with the question: what other methods offer possibilities of weevil control, particularly for the protection of existing plantations of white pine and other species, notably Norway spruce and Scots pine, that have been established in recent years and are now being subjected to serious injury by the weevil?

White pine weevil populations are much more stable numerically than many other forest insect populations that are characterized by violent fluctuations in numbers resulting in outbreaks separated by periods of time when numbers of the insect are very low. Moreover, the weevil does not kill its host as do many of the truly "epidemic" insect species. The weevil is, therefore, well adjusted to its environment, and as a well adjusted organism, it has numerous biological agents that keep its numbers in check. Birds, small mammals, and insect predators and parasites have been observed taking an annual toll of both larvae and adults. It has been estimated in the eastern United States $(19,20)$ that birds and insect predators and parasites together may be responsible for reducing the weevil population yearly by as much as $30 \%$, and while the importance of small mammals as control agents has not been investigated closely, they undoubtedly take their toll of adults during the spring and autumn. Disease does not seem to be a factor in natural control. However, the prospects of controlling the weevil by biological means do not appear promising. The possibilities of developing strains of white pine and Norway spruce resistant to weevil attack are presently being investigated (9), but work has not yet progressed to the stage where suspected resistant types have been tested under field conditions. This work will, of necessity, be of a very long term nature, but the possibilities which it offers are great.

Direct control measures to reduce populations have long been practiced. As early as 1817 Peck (13) recommended the removal and destruction of 
infested leaders. Later workers $(1,10)$ recommended that leaders be removed but placed in screen cages which would permit the escape of insect parasites but not the weevil adults. For many years a program of removing infested leaders was practiced in the Eli Whitney Forest in Connecticut, starting as soon as weevilling was first detected (12). The results of this program indicated that weevil populations were reduced and permanent damage to attacked trees was minimized, since removal of infested leaders tended to stimulate the lateral which succeeded as the leader to straighten up more rapidly. In some areas vigorous programs of pruning leaders have resulted in holding populations to a level below that necessary to cause economic damage (11). Pruning of infested leaders is, however, an expensive operation, particularly in larger trees, and must be thoroughly carried out for a number of years for satisfactory results.

Attempts to reclaim white pine stands that have suffered extensive weevilling have also been successful $(2,3,4)$. Crop trees with good butt logs have been obtained by selecting co-dominant and intermediate trees that have escaped serious injury, and favoring them as final crop trees by girdling or removing the badly damaged trees.

Attempts to protect plantation trees through the application of chemical sprays from the air and from the ground have only recently proved satisfactory. Many spray formulations have been tested, but to date lead arsenate and DDT have produced the best results $(6,14,16)$. In ground application, the insecticide is applied only to the leaders in the early spring, so that a toxic deposit is present during adult feeding preceding oviposition. Lead arsenate has been favored by recent workers chiefly because it leaves a visible deposit, adheres well to the leader, and has no contact action. It therefore does not affect weevil parasites and other insects that might come in contact with it. Spray programs are recommended with the object of protecting young trees during the period of maximum susceptibility to weevil attack, but usually not after one clear butt $\log$ is assured. The sprays are applied by means of packsack hand sprayers, and several trials have indicated that up to 350 trees may be treated per man hour. Costs of from $\$ 2$ to $\$ 5$ per acre per treatment have been reported from recent operations in both Canada and the United States, using both lead arsenate and DDT formulations. Excellent control is reported, and even in areas of heavy weevil populations, reinfestation of sprayed areas has been slow and single spray operations have effected adequate protection for as long as four years. Best results have been obtained when spraying programs have been undertaken in young stands as soon as the first indications of weevilling are observed. More than one treatment is required, but the three or four years protection afforded by a single treatment, calls for not more than three treatments timed to correspond with reinfestation of about $5 \%$ of the leaders and should thus be sufficient to bring trees through to where they will produce at least one clear butt log.

After World War II, the aerial application of insecticides and sprays became common, and experiments in the control of the weevil by aerial spraying were begun in New York State (5). In trials since 1950, DDT sprays at concentrations of $4 \mathrm{lb} . / 4$ gal. per acre and $2 \mathrm{lb} . / 2$ gal. per acre, applied by 
fixed-wing aircraft and helicopter respectively, have been successful in reducing weevil populations below economic levels, and have afforded protection to plantations for two or three years. Sprays were applied in the spring after adult emergence but before the onset of oviposition, at a cost of from $\$ 2.50$ to $\$ 4.00$ per acre.

It is almost certain that no spray program can eliminate the weevil from a plantation, but populations can, at relatively low cost, be reduced and maintained at levels that will ensure adequate crop trees by this means.

Assuming that our present research will be fruitful, two methods of growing white pine satisfactorily free of weevil damage are evident:

1) Growing pine in mixture with other species, thereby providing the shading necessary to keep weevilling at a minimum.

2) Growing pine in pure stands, keeping weevil populations at an acceptable level by means of chemical sprays applied either from the ground or from the air.

Which method is better under any particular circumstance must be left to the decision of the silviculturist, based on the many silvicultural, economic, and biological considerations which have a bearing on the problem. One approach might well be the judicious blending of both methods of protection - the establishment and maintenance of a cover crop to provide sufficient shade to keep weevilling within acceptable limits and yet permit as good growth of the pine as possible, with chemical sprays being employed to give added protection if unusual conditions result in an increase of the weevil populations beyond a tolerable level.

\section{REFERENCES}

1. BLACKMAN, N. W., 1919. Report on the white pine weeril. Maine For. Dept.

2. CLINE, A. C. and H. J. MACALONEY, 1931, A method of rechaiming severely weeviled white pine plantations. Mass. For. Assoc. Bull. 152:3-11.

3. CLINE, A. C. and H. J. MACALONEY, 1933. Additional notes on the improvement of weeviled white pine plantations. Conn. Forest and Park Assoc. Pub. 24:1-11.

4. CLINE, A. C. and H. J. MACALONEY, 1935. Progress report of the reclammation of eeverely weeviled white pine plantations. J. For. $33(11)$.

5. CONNOLA, D. P., T. MeINTYRE, and C. J. YOPS, 1955. White pine weevil control by aircraft spraying. J. For. 53:889-891.

6. CROSBY, D., 1950. Concentrated lead arsenate spray for control of white pine weevil. J. For. 48:334-336.

7. GRAHAM, S. A., 1918. The white-pine weevil and its relation to second-growth white pine. J. For. 16:192-202.

8. GRAHAM, S. A., 1926. Biology and control of the white-pine weevil, Pissodes strabi Peck. Cornell Univ. Agric. Exp. Station Bull. 449.

9. HOLST, M. J., 1955. Breeding for weevil resistance in Norway Spruce. Forest Genetics and Forest Tree Breeding. 4:33-37.

10. HOPKINS, A. D., 1907. The white-pine woevil. U.S.D.A. Bur. Ent. Circ, 90. 
11. MACALONEY, H. J., 1930. The white-pine weevil (Pissodes strobi Peck). Its biology and control. N.Y. State Coll. For. Bull. No. 3.

12. MAUGHAN, W., 1930. Control of the white pine weevil on the Eli Whitney forest. Yale Univ. School of Forestry Bull. No. 29.

13. PECK, W. D., 1817. On the insects which destroy the young branches of the pear-tree, and the leading shoot of the weymouth-pine, Mass. Agr. Jour. 4:205-211.

14. POTTS, S. F., A. C. CLINE and H. L. McINTYRE, 1942. The white pine weevil and its control by the application of concentrated sprays. J. For. 40:405-410.

15. PREBBLE, M. L., 1951. Unpublished Report, Forest Insect Laboratory, Sault Ste. Marie, Ontario.

16. SHENEFELT, R. D., 1951. A further note on the control of the white pine weevil. J. For. 49:575-576.

17. SPURR, S. H. and R. B. FRIEND, 1941. Compression wood in weeviled northern white pine. J. For. 39:1005-1006.

18. SULLIVAN, C. R., 1953. Use of radioactive cobalt in tracing the movements of the whitepine weevil, Pissodes strobi Peck. Canad. Ent. 85:273-276.

19. TAYLOR, R. L., 1929. The biology of the white pine weevil, Pissodes strobl (Peck), and a study of its insect parasites from an economic viewpoint. Ent. Amer. 9:167-246.

20. TAYLOR, R. L., 1930. The biology of the white pine weevil, Pissodes strobt (Peck), and a study of its insect parasites from an economic viewpoint. Ent. Amer. 10:1-86. 